\title{
Remote sensing reflectance reconstruction to obtain water optical properties from MERIS multi-spectral satellite images
}

\author{
Marjorie Schmeltz ${ }^{\mathrm{a}}$, Jean-Marie Froidefond ${ }^{\mathrm{a}}$, Frédéric Jourdin ${ }^{\mathrm{b}}$ and Peter Gege ${ }^{\mathrm{c}}$ \\ ${ }^{a}$ Université de Bordeaux 1, UMR 5805, avenue des facultés, 33405 Talence, France \\ ${ }^{\mathrm{b}}$ Service Hydrographique et Océanographique de la Marine (SHOM), 29228 Brest, France \\ ${ }^{c}$ DLR Remote Sensing Technology Institute, Oberpfaffenhofen, D-82234 Wessling, Germany
}

\begin{abstract}
We use a multiple regression analysis and a data bank of about 400 reflectance spectra to reconstruct hyperspectral reflectances between 400 and $900 \mathrm{~nm}$ with a $5 \mathrm{~nm}$ step using only the values known at the wavelengths of the MERIS sensor level 2 data. For in situ remote sensing reflectances measured during different oceanographic missions, the reconstruction is within 2 per cent almost over the entire spectrum. The main difference (to a maximum of 4 per cent) usually occurs at the inflexion point of the reflectance curve between 580 and $600 \mathrm{~nm}$. Observed in-situ remote sensing reflectances or reconstructed spectra are inverted using a Water Colour Simulator bio-optical model (WASI) to obtain the inherent optical properties (IOP) of the water. The values derived by the model are compared with the measurements when available. To validate the reconstruction, we compare the results of the model inversion using the initial spectrum or the reconstructed one as input. Preliminary results show that the derived values from the inversion of the reconstructed spectrum are very close to the values generated from the inversion of the initial spectrum, especially in case 1 waters. This reconstruction technique is used to generate hyperspectral remote sensing reflectances from reflectance data calculated by the MERIS sensor. We use the reconstructed spectra as input to be inverted in the WASI model in order to quantify the substances' concentrations; in particular, the inversion is working well for the suspended particulate matter concentrations.
\end{abstract}

Keywords: Coastal turbid waters; In-situ ocean colour measurements; WASI bio-optical model; Reflectance; Attenuation depth; CDOM.

\section{INTRODUCTION}

About 400 hyperspectral Remote sensing reflectance (Rrs) spectra of the surface water were obtained with a TRIOS spectroradiometer mounted on a mini-catamaran [1] over different areas (Bay of Biscay, Mediterranean Sea, French Guiana shelf, off New Caledonia and Gabon coast). Simultaneously, hydrologic measurements (CTD, fluorescence, attenuation, scattering) and water samples were collected to measure suspended particulate matter (SPM), Chlorophyll-a and coloured dissolved organic matter (CDOM) concentrations. These optical measurements were carried out to determine the relationship between the water components and the remote sensing reflectance (Rrs). In the past, we have obtained several relationships between the suspended matter concentrations and the Rrs [2], [3]. But these relationships are empirical and with a low precision. Moreover, it was impossible to obtain CDOM and Chlorophyll-(Chla) concentrations in the case 2 waters. Consequently, the Water colour Simulator software (WASI, [4]) was selected to invert in-situ reflectance spectra. The satellite sensors MODIS and MERIS have multispectral channels and these data, although fit to be used as is in WASI, will only give multispectral inverted results and cannot be directly compared with our observed measurements. We use a multiple regression analysis and a data bank of over 400 reflectance spectra to reconstruct hyperspectral reflectances between 400 and $900 \mathrm{~nm}$ with a $5 \mathrm{~nm}$ step using only the values at the 15 wavelengths of the MERIS sensor $(412.5,442.5,490,510,560,620,665,681.25,708.75,753.75,760.625,778.75,865$, $885,900)$. Then, these reconstructed spectra are used as inputs and inverted by WASI to obtain the Inherent Optical 
Properties $a(\lambda), b_{b}(\lambda), \operatorname{Kd}(\lambda)$ and the water components SPM, Chla, CDOM concentrations. Different examples are processed to assess the accuracy of this method.

\section{DATA AND METHOD}

Data are constituted from hyperspectral (Rrs spectra) and hydrological measurements obtained at specific locations (SPM, Chla, CDOM, temperature, salinity) at different depths. The method, the objective of which is to know the composition of the water, includes several steps: 1) extraction of the ENVISAT/MERIS or MODIS/Aqua data at a given point, 2) Reconstruction of the Rrs spectrum using a multiple regression code, 3) WASI inverse modelling to obtain the main three water components (SPM, Chla and CDOM).

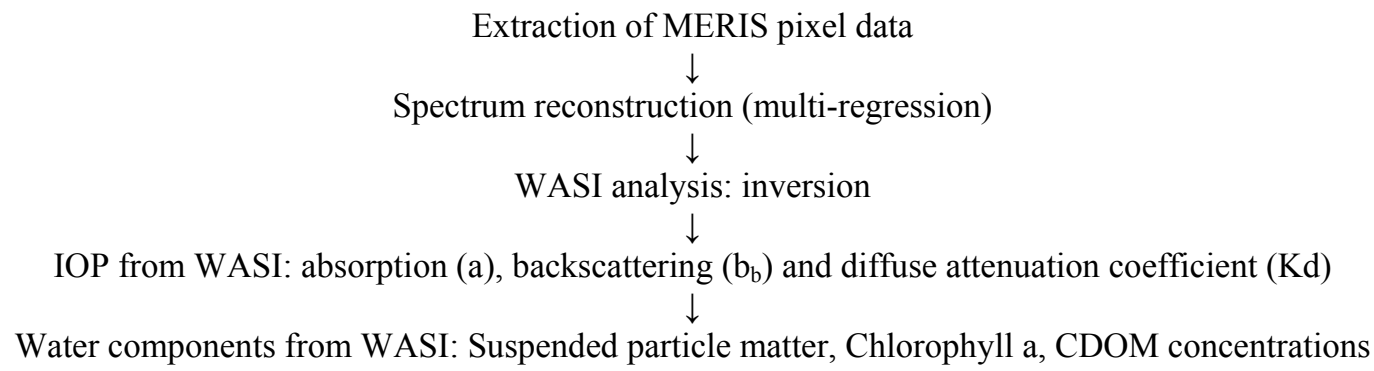

\subsection{Optical measurements}

The optical measurements were carried out using TRIOS RAMSES sensors, which measure simultaneous atmospheric downwelling irradiances $E_{d}$ and in-water upwelling radiances $L_{u}$ in the 350-900nm range, as well as other optical sensors (transmissometer, fluoremeters, turbidimeters) on a CTD data logger. The irradiance spectroradiometer was settled on the ship. The two radiance spectroradiometers were fixed on a platform (mini-catamaran): one with the quartz window just below the sea surface $(-2 \mathrm{~cm})$, the other slightly above the sea surface, Figure 1. [1].

The radiance sensors were calibrated before the surveys and calibrated as in air, according to Trios specifications (even if the sensor is actually located below the water surface).

The irradiance sensor is located at the top of the ship and not on the platform, because the ship movement is relatively low in term of sun angle, unlike the movement of the small platform. The remote sensing reflectance is calculated as follows [5]:

$$
R_{r s}(\lambda)=t \times L_{u}(0-, \lambda) / E_{d}(0+, \lambda)
$$

where $t$ is the transmittance $(0.98)$ of the air-sea interface [1].

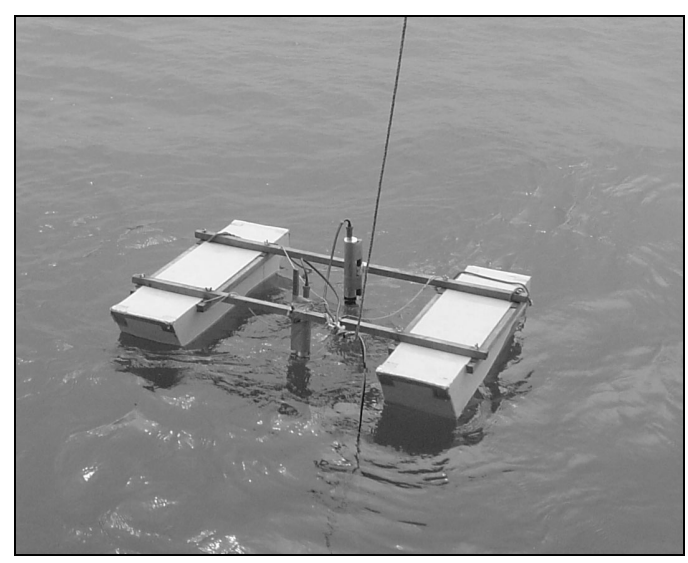


Figure 1. Mini-catamaran used to measure the radiance spectra above and below the interface $(\approx-2 \mathrm{~cm})$. The irradiance sensor is located at the top of the oceanographic vessel.

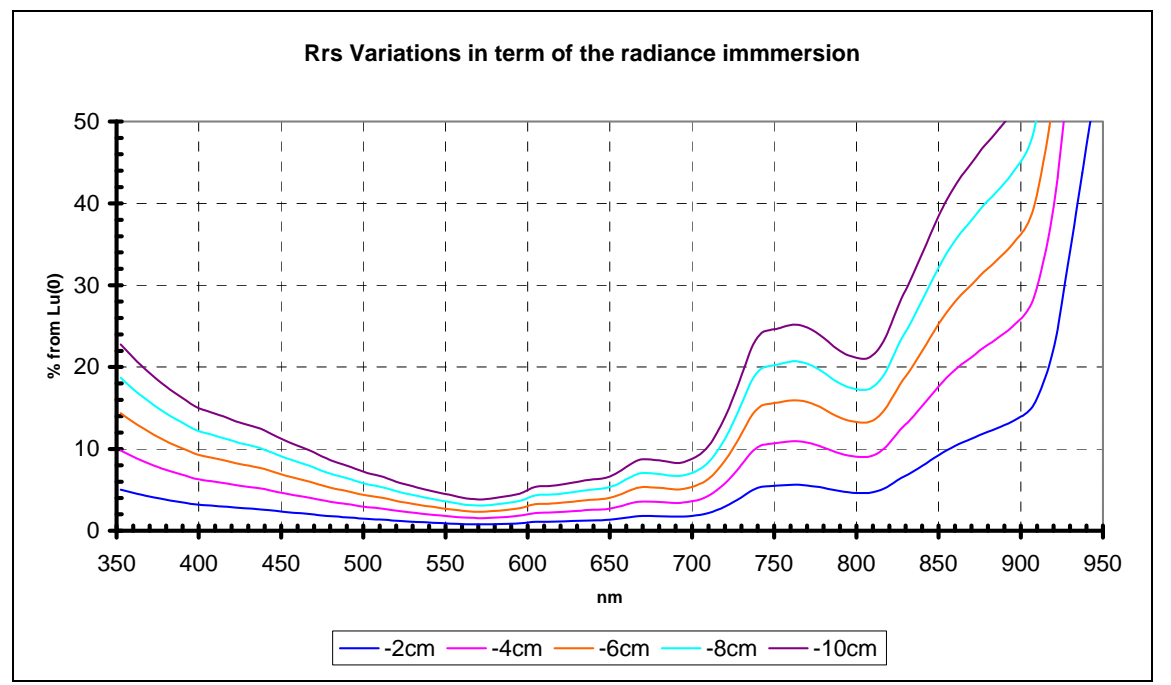

Figure 2. From Hydrolight simulations [7] Rrs changes in \% with the radiance sensor window at different depths below the sea surface $(-2 \mathrm{~cm},-4 \mathrm{~cm},-6 \mathrm{~cm},-8 \mathrm{~cm},-10 \mathrm{~cm})$ for $0.5 \mathrm{mg} \cdot \mathrm{m}^{-3}$ (chlorophyll a), $0.5 \mathrm{~m}^{-1}$ (CDOM) and $1 \mathrm{mg} \cdot \mathrm{L}^{-1}$ (SPM).

From Hydrolight simulations [6], [7], for the low concentrations, in the UV (350-400nm), Rrs decreases by 4\% with an immersion of $-2 \mathrm{~cm}$ and up to $20 \%$ for $-10 \mathrm{~cm}$ (figure 2). In the visible domain, between 400 and $700 \mathrm{~nm}$, the decrease is lower, about $2 \%$, with the window sensor at $-2 \mathrm{~cm}$. In the near infrared, the decrease is higher. In coastal waters, when the SPM concentration is higher, for instance $10 \mathrm{mg} . \mathrm{L}^{-1}$, the immersion depths have larger effects, giving a decrease of $10 \%$ in the UV, $4 \%$ in the visible and $10 \%$ in the NIR, for the sensor at $-2 \mathrm{~cm}$.

\subsection{Hyperspectral data base}

The hyperspectral reflectance measurements $(\operatorname{Rrs}(\lambda))$ were collected following the process mentioned above between 2004 and 2010. At each station, 30 to 50 spectra were recorded 5 to 10 seconds apart over a few minutes. The average spectrum with the standard deviation is computed. About 400 average spectra were collected from several surveys carried out in the case 2 waters in the Bay of Biscay off the Gironde and the Adour estuaries, off the Rhône River (Mediterranean Sea), along the Gabon and Congo Africa coast (Bay of Guinea), off the Noumea lagoon (New Caledonia) and the French Guiana. At each station, hydrological data are also measured, such as the SPM, Chla and CDOM concentrations. Unfortunately, the CDOM and the Chla concentrations are not available for each survey.

Table 1. In situ data of the hyperspectral data base

\begin{tabular}{|c|c|c|c|c|c|c|}
\hline Surveys & Dates(jj/mm/y) & Location & Spectra nbr & SPM & Chl-a & CDOM \\
\hline PRECHICO & $7-13 / 04 / 1999$ & French Guiana & 17 & 17 & 17 & no \\
\hline MODYCOT-4 & $24 / 03-3 / 04 / 2003$ & Bay of Biscay & 44 & 38 & 20 & yes \\
\hline ELISA-7 & $1-6 / 05 / 2004$ & Fr. Guiana & 15 & 15 & 15 & no \\
\hline OPTIC-PCAF & $11-18 / 10 / 2004$ & Bay of Biscay & 11 & 11 & 11 & yes \\
\hline OPTIC-G0 & $5-10 / 02 / 2005$ & Gironde estuary & 29 & 33 & 32 & no \\
\hline OPTIC-CONGO & $2-29 / 03 / 2005$ & Gabon and Congo & 63 & 41 & 58 & yes \\
\hline OPTIC-G1 & $2-8 / 07 / 2005$ & Gironde estuary & 49 & 49 & no & no \\
\hline BISSECOTE & $1-14 / 02 / 2006$ & New Caledonia & 22 & 22 & 22 & no \\
\hline OPTIC-G2 & $24-29 / 032006$ & Gironde estuary & 36 & 32 & 15 & no \\
\hline OPTIC-G3 & $24-30 / 092006$ & Gironde estuary & 30 & 25 & 23 & no \\
\hline
\end{tabular}




\begin{tabular}{|c|c|c|c|c|c|c|}
\hline BATEL-1 & $4-12 / 06 / 2007$ & Basque country & 85 & 85 & 15 & yes \\
\hline OPTIC-MED & $4-14 / 05 / 2008$ & Mediterrannean & 47 & 47 & 47 & yes \\
\hline BATEL-2 & $11-13 / 06 / 2009$ & Basque country & 53 & 53 & 53 & yes \\
\hline
\end{tabular}

\subsection{Reconstruction from a multiple regression code.}

In the visible and near infrared domains, the available satellite data are multispectral with, for example 15 bands for ENVISAT/MERIS. With the WASI code used to invert the Rrs, it is best to use hyperspectral curves as inputs for maximum information. Consequently, a multiple regression code was obtained from the spectra data bank, following the Wernand et al. (1997) method [8].

Any spectrum can be decomposed as follows:

The proposed technique is to express the full reconstructed spectrum $R(\lambda)$ as a linear combination of a constant and the reflectance at points where the spectrum is known:

$$
\mathrm{R}(\lambda)=\mathrm{b}_{0}(\lambda)+\Sigma_{(\mathrm{i}=1, \mathrm{I})}[\mathrm{bi}(\lambda) \mathrm{R}(\mu \mathrm{i})]
$$

Here, the functions bi $(\lambda)$ are derived from the hyperspectral data base (HDB) with 400 spectra and $\mu 1, \mu 2, \mu 3 \ldots$ are the wavelength where the spectrum is known from the satellite sensor.

When it is attempted to reconstruct a spectrum $\mathrm{R}_{\mathrm{k}}(\lambda)$ of the HDB itself using equation $(2)$, an error $\operatorname{\varepsilon k}(\lambda)$ will remain:

$$
\mathrm{R}_{\mathrm{k}}(\lambda)=\mathrm{b}_{0}(\lambda)+\Sigma_{(\mathrm{i}=1, \mathrm{I})}\left[\mathrm{b}_{\mathrm{i}}(\lambda) \cdot \mathrm{R}_{\mathrm{k}}(\mu \mathrm{i})+\varepsilon_{\mathrm{k}}(\lambda)\right], \mathrm{k}=1, \ldots, \mathrm{K}
$$

For example, with MODIS data, the number points I equals 10 (10 bands) and the number of spectra in the HDB is K (400). The functions bi $(\lambda)$ are determined by a multiple regression analysis. It is required that the sum of squared errors $\Sigma \varepsilon^{2}{ }_{\mathrm{k}}$ is as small as possible for each wavelength $\lambda$. Equation (3) is expressed in matrix form, as follows [8].

$$
A=\begin{array}{ccc}
1 R_{1}\left(\mu_{1}\right) \ldots R_{1}\left(\mu_{I}\right) & b_{0}(\lambda) & R_{1}(\lambda) \\
1 R_{2}\left(\mu_{1}\right) \ldots . R_{2}\left(\mu_{I}\right) & b_{0}(\lambda) & R_{2}(\lambda) \\
& b(\lambda)=b_{1}(\lambda) / b_{I}(\lambda) & \text { and } r(\lambda)=R_{2}(\lambda) / R_{k}(\lambda)
\end{array}
$$

$1 \mathrm{R}_{\mathrm{k}}\left(\mu_{1}\right) \ldots \mathrm{R}_{\mathrm{k}}\left(\mu_{\mathrm{I}}\right)$

Equation (2) can be expressed as $r(1)=A b(\lambda)+\varepsilon(\lambda)$ and for $b(\lambda)$ it is found:

$b(\lambda)=\left(A^{T} A\right)^{\text {inv }} A^{T} \cdot r(\lambda)$, where $A^{T}$ is the matrix transpose of $A$.

With this equation for $b(\lambda)$ and with $\mu_{1} \ldots \mu_{15}$ (MERIS) the regression coefficient were computed. Using these coefficients, any spectrum can be reconstructed of which only $R\left(\mu_{1}\right), \ldots R\left(\mu_{10}\right)$ are known from the satellite sensor (Input: MERIS bands $(15)=[412.5,442.5,490,510,560,620,665,681.25,708.75,753.75,760.625,778.75,865$, $885,900]$.Output: Reconst. Bands (120) $=350$ - 950nm, with 5nm step).

To validate the reconstruction process, we used different measured spectra $\operatorname{Rrs}(\lambda)$. From those, the equivalent MERIS and MODIS data were selected. Then, these MERIS and MODIS values were used to reconstruct the spectra (Figure 3). Finally, the reconstructed spectra are compared with the original spectra. The differences between both spectra (original and reconstructed) are displayed. The differences are generally lower than $5 \%$ (Figure 3 ).

\subsection{WASI inverse modelling}

We use version 3 of the Water colour Simulator software (WASI), [4] to invert in-situ reflectance spectra. WASI integrates forward and inverse modelling for eight common types of optical in-situ measurements in aquatic environments (in particular remote sensing reflectance, absorption or attenuation), using well-established analytical models. In inverse mode, the input spectra are analyzed by fitting some parameters: phytoplankton concentration, large and small suspended particles concentration, concentration of yellow substance (CDOM), and bottom reflectance. Previous results show that the software is generally able to reproduce very well the reflectance spectra [9]. Different reflectance models can be selected by the user.

In the present study, the following algorithm was chosen for the irradiance reflectance [10]: 


$$
R(\lambda)=E_{u}^{-}(\lambda) / E_{d}^{-}(\lambda)=f *\left[b_{b}(\lambda) /\left(a(\lambda)+b_{b}(\lambda)\right)\right]
$$

$f$ is a constant value of $0.33, a(\lambda)$ is calculated from the absorption coefficients of chlorophyll, mineral particles and CDOM and $b_{b}(\lambda)$ is obtained from the water, the mineral particles and the chlorophyll backscattering coefficients.

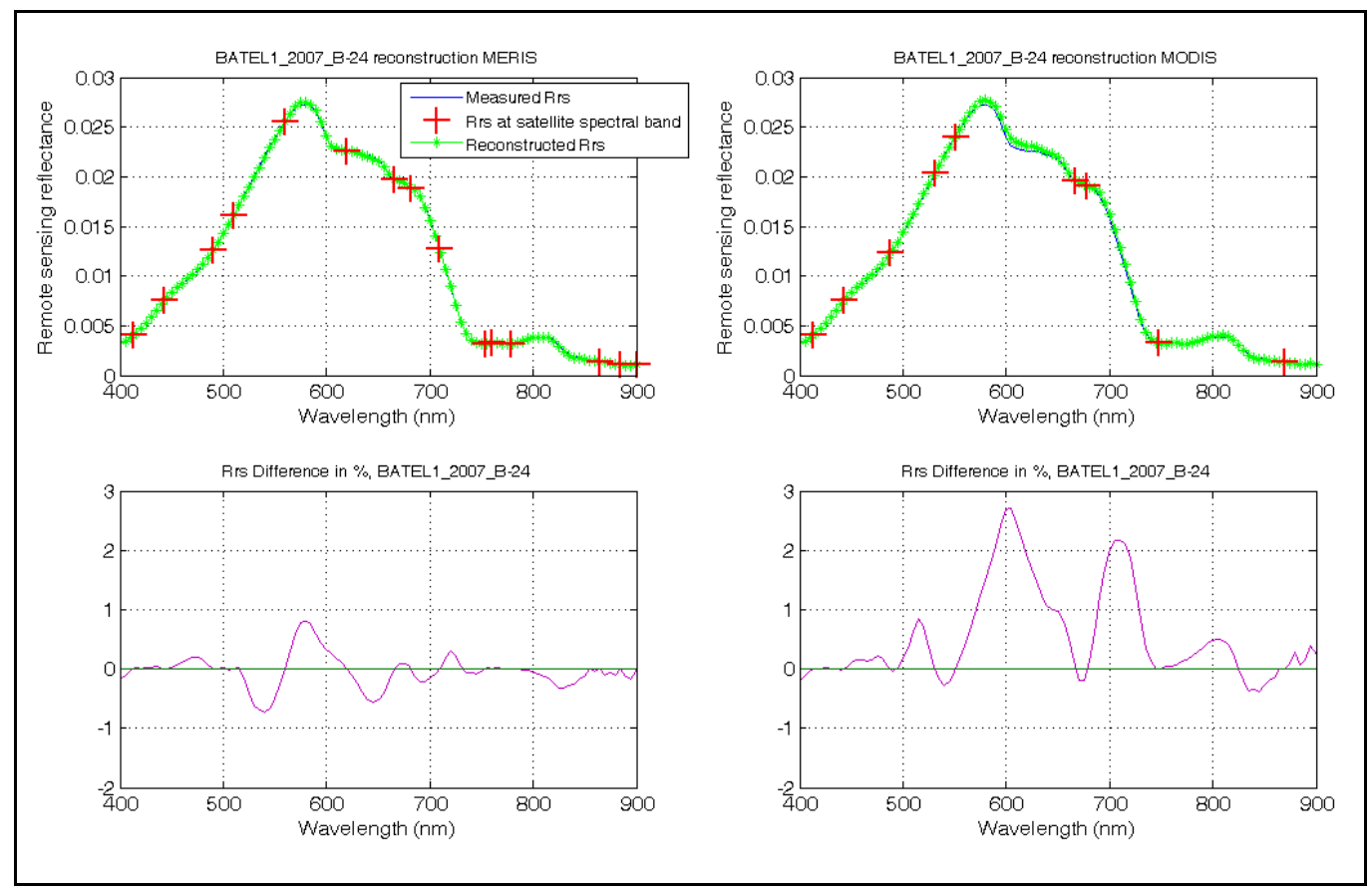

Figure 3. Comparison between measured spectra and spectra reconstructed from MERIS and MODIS bands.

In the WASI model, we chose the remote sensing reflectance $R_{r s}(\lambda)[10]$ to be defined as:

(i) Below water surface:

$$
R_{r s-}(\lambda)=f_{r s} * R(\lambda)
$$

where $\mathrm{f}_{\mathrm{rs}}$ is from [10]: f_rs $=\mathrm{p} 1 *\left(1+\mathrm{p} 2 * \mathrm{x}+\mathrm{p} 3 * \mathrm{x} 2+\mathrm{p} 4 * \mathrm{x} 3 *\left[1+\mathrm{p} 5 / \cos \left(\operatorname{sun}_{-} \mathrm{w}\right)\right] *[1+\mathrm{p} 7 / \cos (\right.$ view_w $)]$

(ii) Above water surface:

$$
R_{r s+}(\lambda)=x_{i} * R_{r s-}(\lambda) /\left(1-\sigma^{-} * R(\lambda)\right)+R_{r s}^{\text {surf }}(\lambda)
$$

where $\quad x_{i}=(1-\sigma) *\left(1-\sigma_{L}^{-}\right) / n_{w}^{2}$

$n_{w}=1.33$ is the refractive index of water. $\sigma, \sigma_{\mathrm{L}}{ }^{-}$and $\sigma^{-}$are the reflection factors for $E_{d}, L_{u-}$ and $E_{u-}$ respectively. In our case, as the spectra are measured just below the surface, $\sigma$ and $\sigma_{\mathrm{L}}{ }^{-}$and $R^{\text {surf }}$ are set to 0 . By default $\sigma^{-}$is set to 0.54 .

Consequently, the input data are the following: 1- depth (m), 2- reflectance bottom if necessary, 3- solar zenith angle, 4Temperature, 5- Type of phytoplankton, 6- Particle size (small or large), and we determine the values of the following parameters by fit: chlorophyll, non chlorophyll particles and CDOM concentrations, and the spectral slope. 
Our objective is to obtain a model reflectance spectrum that best fit the measured spectrum and the three component concentrations (the bottom depth and the solar zenith angle are prescribed). The fit parameters (chlorophyll, suspended particulate matters, yellow substance concentrations, particle size, (larger or smaller than 5 microns), spectral slope) are determined iteratively using the method of nonlinear curve fitting. At iteration 1, a model spectrum is calculated using initial values for the fit parameters. This is the best way to reduce all types of inversion problems. Initial values are selected by the user. Furthermore, an automatic method is implemented for $R$ and $R_{r s}$ spectra ([11], [12], [13]). The model spectrum is compared with the measured spectrum by calculating the residuum as a measure of correspondence [14]. WASI uses the Simplex algorithm. The wavelength range of the outputs is 350-900 nm with a $1 \mathrm{~nm}$ interval, however the fitting is performed for a single spectrum in the 400-900 nm range to avoid forcing the model to data that are less reliable (below $400 \mathrm{~nm}$ ). After inversion, an overlay of the spectrum and fitted curve is automatically shown on screen and the resulting fit values, number of iterations, and residuum are displayed.

\subsection{Output parameters and IOP determination}

From this inverse modelling, the WASI software calculates the absorption $\left(\mathrm{a}_{\mathrm{wc}}(\lambda)\right)$ and the backscattering $\left(\mathrm{b}_{\mathrm{b}}(\lambda)\right)$ spectra.

$$
\mathrm{a}_{\mathrm{wc}}(\lambda)=\Sigma \mathrm{Ci} \cdot \mathrm{a}_{\mathrm{i}} *(\lambda)+\mathrm{X} . \mathrm{a}_{\mathrm{x}}^{*}(\lambda)+\mathrm{Y} . \mathrm{a}_{\mathrm{y}} *(\lambda)
$$

$a_{w c}(\lambda)$ : absorption of water constituents, $a_{i}^{*}(\lambda):$ chlorophyll absorption, $a_{x}{ }^{*}(\lambda)$ : non chlorophyll absorption, $a_{\mathrm{y}}{ }^{*}(\lambda)$ : coloured dissolved organic matter.

The backscattering coefficient $b_{b}$, expressed as follows:

$$
b_{b}(\lambda)=b_{b w}(\lambda)+C_{L} \cdot b_{b L}^{*} \cdot b L(\lambda)+C s \cdot b_{b s}^{*} \cdot(\lambda / \lambda s)^{n}
$$

is the sum of backscattering by pure water $\left(b_{b w}\right)$ and suspended matter (large particles $b_{b L} * b L(\lambda)$ and small particles $\left.b_{b s}^{*} \cdot(\lambda / \lambda s)^{n}\right)$.

If the bottom depth is given, the software calculates the attenuation coefficient $\mathrm{K}_{\mathrm{d}}$, which describes attenuation for downwelling irradiance, expressed as:

$$
E_{d}(z, \lambda)=E_{d}(0, \lambda) \cdot \exp ^{-\left[K_{d}(\lambda) \cdot z\right]}
$$

The following parameterization of $\mathrm{K}_{\mathrm{d}}$ is adapted from [10] and [14]:

$$
K_{d}=\kappa_{0} \cdot\left(a+b_{b}\right) / \cos \left(\theta_{s}^{\prime}\right)
$$

with $\kappa_{0}=1.0546 \pm 0.0001$, and $\cos \left(\theta_{\mathrm{s}}{ }^{\prime}\right)$, the cosines of the solar zenith angle below the water surface $\operatorname{such}$ that $\mathrm{n} 1 . \sin (\theta \mathrm{s})=$ $\mathrm{n} 2 \cdot \sin \left(\theta \mathrm{s}^{\prime}\right), \mathrm{n} 1$ and $\mathrm{n} 2$ being the refractive indices of air and water respectively $(\mathrm{n} 1=1$ and $\mathrm{n} 2=1.33)$.

The depth of penetration of light ( $Z_{90}$, in meters) above which $90 \%$ of the diffusely reflected irradiance (excluding specular reflectance) originates for a homogeneous Ocean is related to the $\mathrm{K}_{\mathrm{d}}$ and expressed as ([15]):

$$
Z_{90}(\lambda)=1 / K_{d}(\lambda)
$$

Using equation (1) in [15], we can also express the depth of penetration of light, $Z_{x}$, above which $\mathrm{x} \%$ of light emerging of the sea originates, for any $\mathrm{x}$ between 0 and 100 .

We have (see [15] for the definition of each variable): 


$$
N_{Z_{x}} / N_{\infty}=x / 100=1-\exp \left[-Z_{x} \cdot c \cdot\left(1-\omega_{0} F\right)(1+\mu) / \mu\right]
$$

which then gives:

$$
\forall x \in\left[0 1 0 0 \left[, Z_{x}=Z_{90} *[\ln (100)-\ln (100-x)] / \ln (10)\right.\right.
$$

Thus,

$$
Z_{50}(\mathrm{~m})=0.3 * Z_{90}(\mathrm{~m})
$$

And

$$
Z_{75}(\mathrm{~m})=0.6 * Z_{90}(\mathrm{~m})
$$

The attenuation of the light is not linear. In the following sections, we will only focus on the penetration depth $Z_{90}$.

For example at station 1602, during the Optic-Congo survey (2005), [16], $\operatorname{Rrs}(\lambda)$ was measured (figure 4), then the radiances in term of depth, to obtain the $\mathrm{Ku}$ (figure 5). From this last data, we obtain the $\mathrm{Z} 90$ from measured $\mathrm{Ku}$ (figure 6). In inverse mode with WASI, it is also possible to obtain the Z90 from the measured $\operatorname{Rrs}(\lambda)$ data, using the inferred $\mathrm{Kd}$ and eq. 12 (figure 6). Different simulations show these results (figure 6). In the same way, from the spectra, it is possible to obtain the absorption (a) and the backscattering coefficients $\left(b_{b}\right)$.

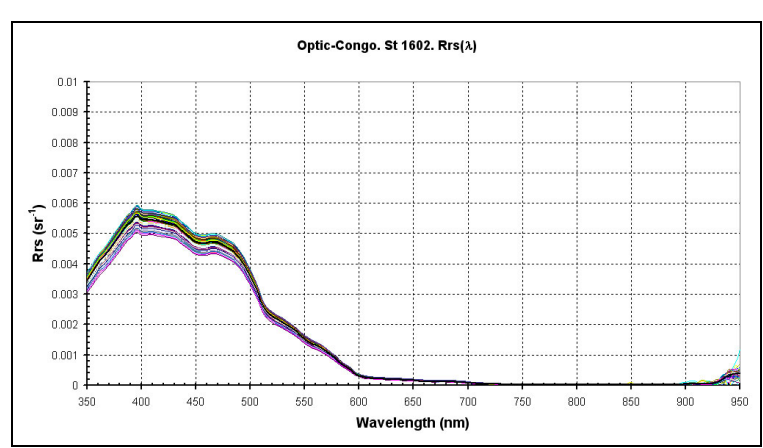

Figure 4: Rrs( $\lambda)$. At St. 1602.

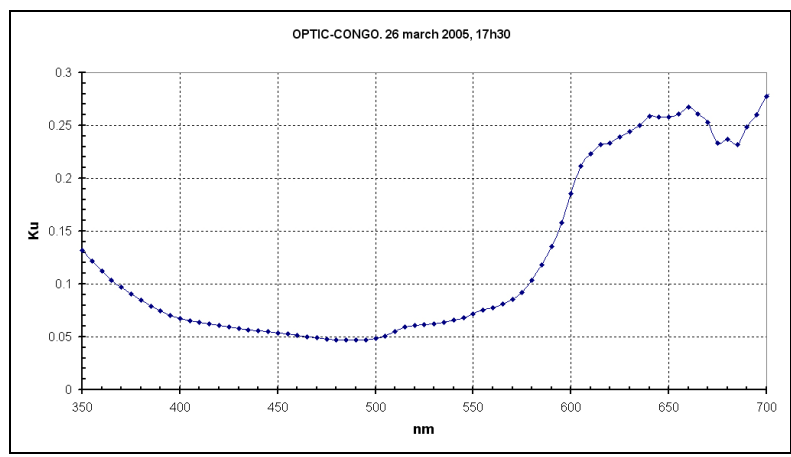

Figure 5: $\operatorname{Ku}(\lambda)$ from radiances in term of depth (St 1602)

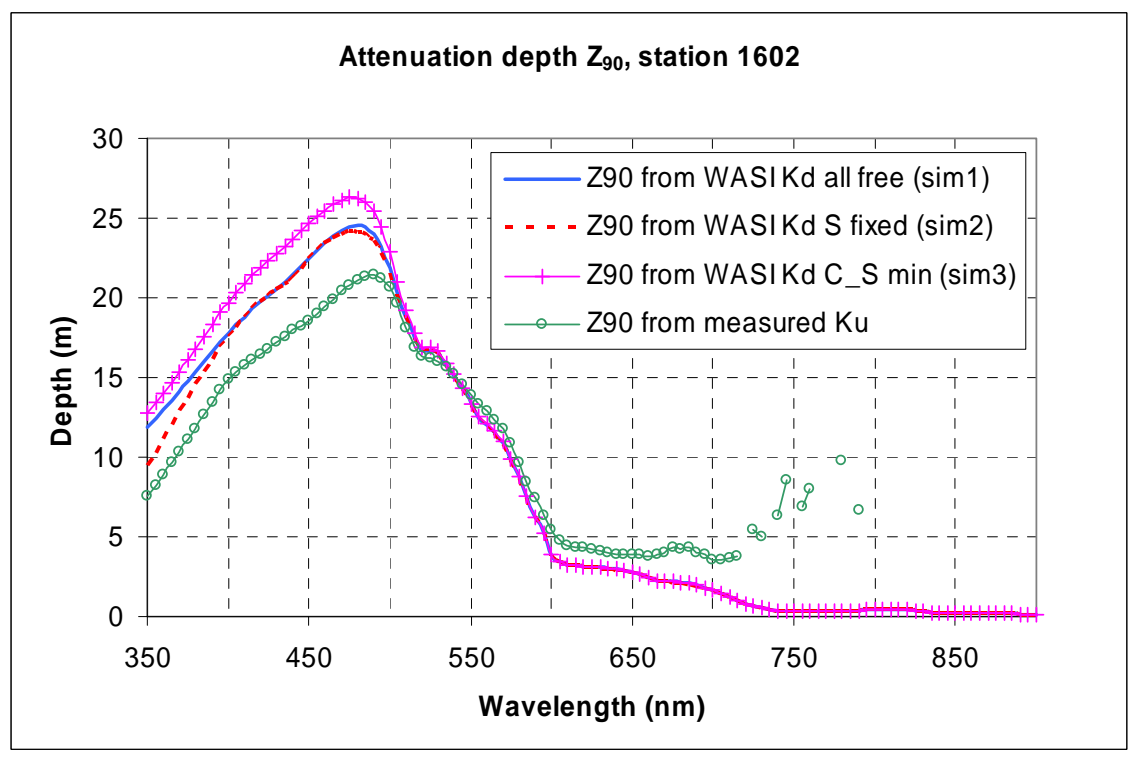




\section{WATER OPTICAL PROPERTIES FROM MERIS DATA}

The objective is to use the level 2 satellite data (ENVISAT/MERIS) to obtain the inherent properties. First, the satellite Rrs data are converted into full spectra with the multiple regression analysis, then the reconstructed MERIS spectra are inverted with WASI to obtain the main coefficients $\operatorname{Kd}(\lambda), a(\lambda), b_{b}(\lambda)$. As an example, the south part of the Bay of Biscay (Basque country, France) was used because it is possible to compare with the Batel-1 survey, carried out in June 2007 [17].

\subsection{Reconstructed spectra}

The ENVISAT/MERIS full resolution level 2 data (ESA, MER_FR_2NEPA.) recorded on June, 5 2007, at 10h41' during the Batel-1 survey (Basque country, France) were downloaded using Eolisa.

From figure 7, we can observe differences between the in situ spectrum and the reconstructed spectrum. These differences may be generated from the atmospheric corrections or from the differences in time acquisition: 10h41' for MERIS and 9h51' for the in situ measurement close to the coast $(5 \mathrm{~km})$.

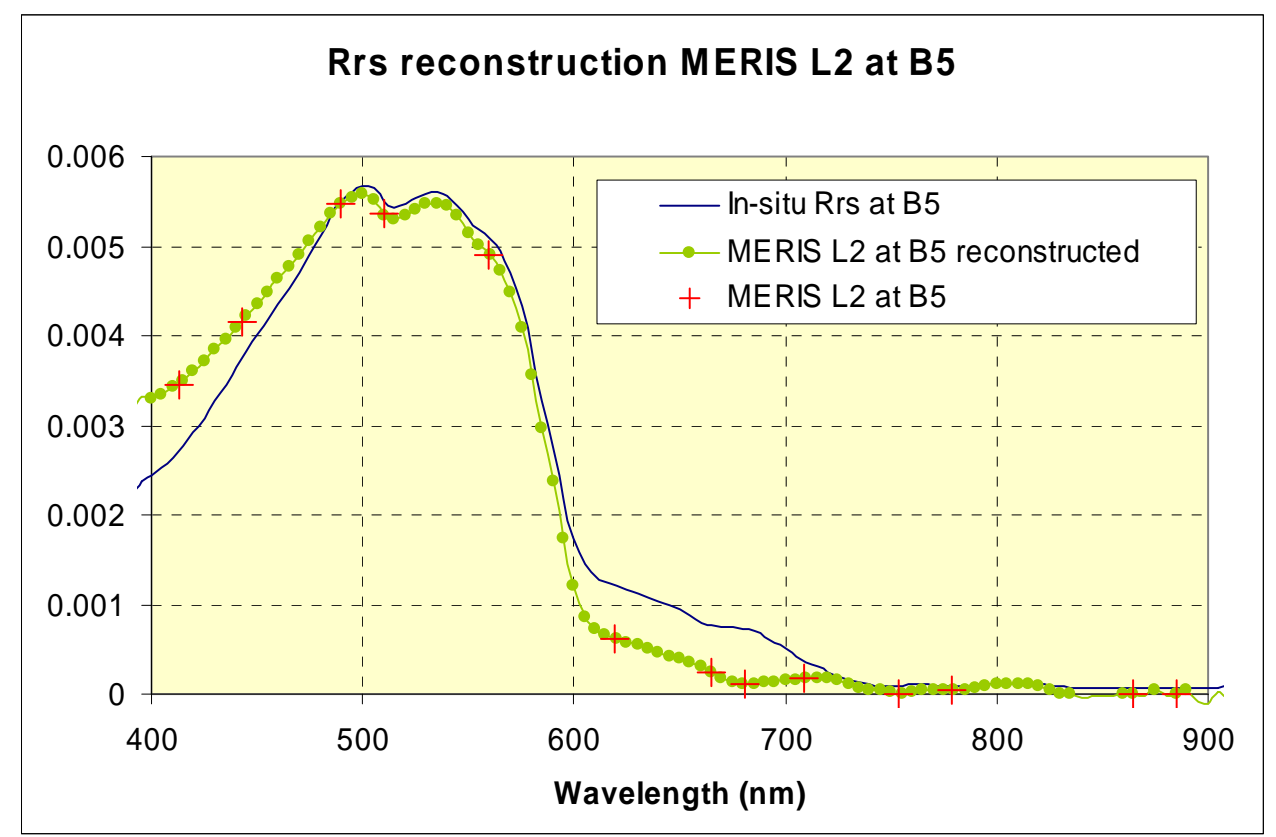

Figure 7: Reconstructed spectra from L2 MERIS data (June, 5, 2007) at the B5 station

\subsection{Inverted data from WASI}

The level 2 MERIS data include the chlorophyll, the SPM and the CDOM concentrations. Thus we can compare these values with the values derived by the WASI inversion of the MERIS reconstructed spectrum at station B5, for example. Figure 8 shows the comparison between in situ values, MERIS L2 values and WASI data by inversion. The SPM concentrations are all close to each other. The values of chlorophyll concentration are scattered. The Z90 at $530 \mathrm{~nm}$ obtained from MERIS spectrum reconstructed and from the in situ spectrum are similar. 


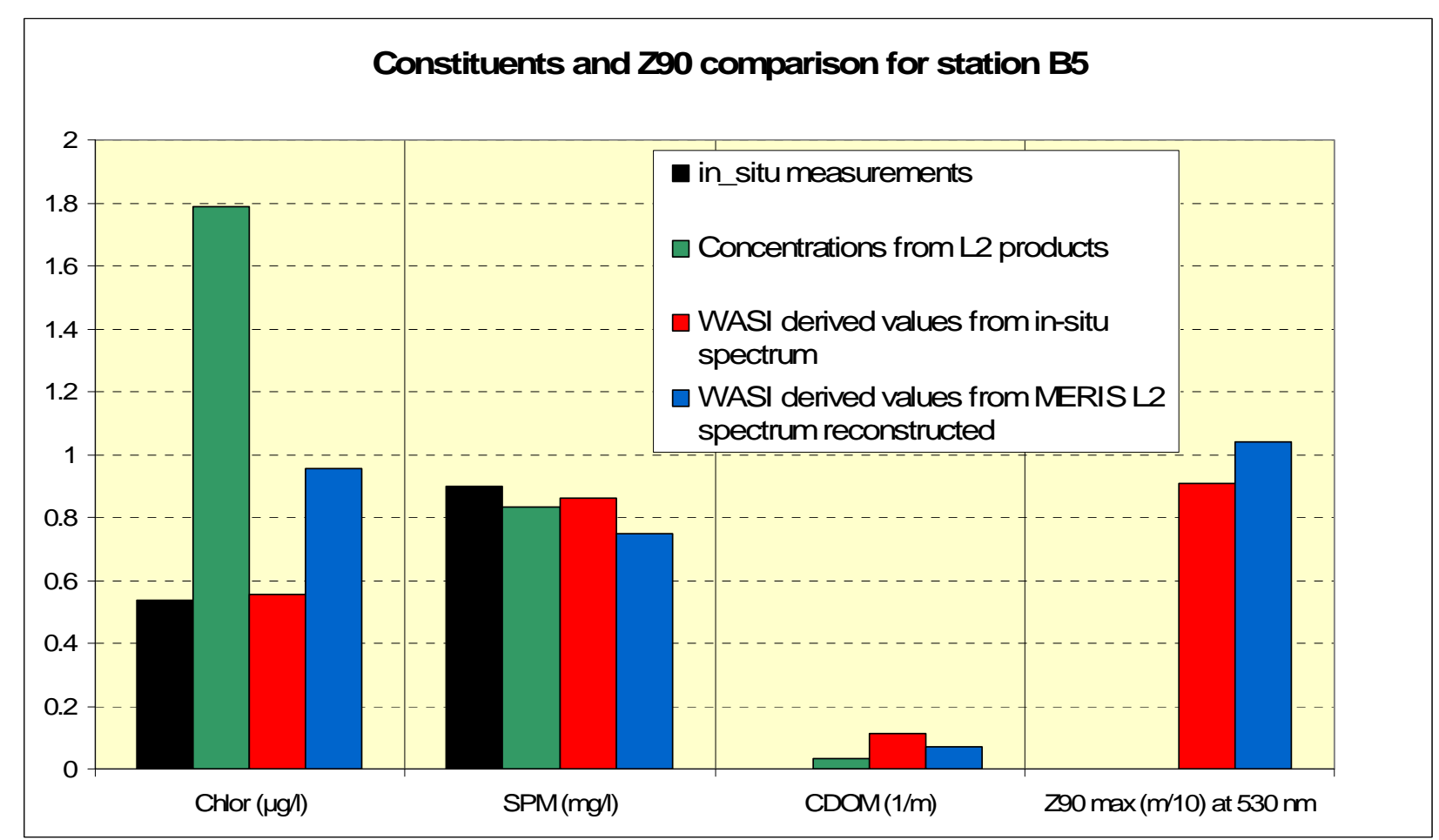

Figure 8: Comparison between in situ measurements, concentrations from MERIS L2 products, WASI derived values from in situ $\operatorname{Rrs}(\lambda)$ and WASI derived values from MERIS L2 spectra reconstructed.

\section{DISCUSSION AND CONCLUSIONS}

The agreement between the observed reflectance curves and the WASI simulations is very satisfactory. The uncertainties in the derived values from WASI compared to the observed ones are mostly dependant on the choice of the model, the choice of the free parameters, the inversion iterations and not on the input reflectance curves. The CDOM spectral slope $\mathrm{S}$ is one of the main unknown. In the different simulations, we first set this parameter free. When the derived value appeared to be out of the range of values found in the literature [18], we force it in a second simulation. As a result, we were not able to reproduce with confidence the chlorophyll-a concentration as this parameter was very sensitive to S. Furthermore, when the chlorophyll concentration is low $\left(<1 \mathrm{mg} \cdot \mathrm{m}^{-3}\right)$, as that was the case in this study, it is difficult to assess the error or the accuracy of the values derived by WASI compared to the measured ones. It is the same for the suspended particulate matter concentration for values below $0.5 \mathrm{mg} / \mathrm{l}$. Between 0.5 and $1 \mathrm{mg} / 1$, the error is still estimated at $50 \%$. WASI is a relatively good and easy software to use to invert the IOP [9].

To apply this WASI inversion to satellite data from MODIS (NASA) or ENVISAT/MERIS (ESA), we developed a multiple regression program adapted from Wernand (1997) [8] to reconstruct hyperspectral reflectances from the multispectral satellite channels (10 bands for MODIS and 15 bands for MERIS). These reconstructed spectra are inverted in WASI to obtain the IOP and substances concentrations. Satellite datasets cover broad areas while data from surveys at sea are very sparse, so this reconstruction is very useful. Combined with the use of WASI-like softwares, it will make it possible to generate better maps of water constituents and quantify parameters (such as the attenuation coefficient Kd) that are difficult to measure. 


\section{ACKNOWLEDGMENTS}

This work was carried out at the EPOC laboratory of the University Bordeaux 1 under a contract with the SHOM that provided financial support for $\mathrm{M}$. Schmeltz (contrat $\mathrm{n}^{\circ} \mathrm{CA} / 2006 / 01 / \mathrm{CMO}$ ). We thank the crew and the scientific team that were involved in the different oceanographic surveys and the spatial agencies (NASA and ESA-AO235). This paper is dedicated to the memory of Mrs Florence Lahet.

\section{REFERENCES}

[1] Froidefond, J.M., Ouillon, S., "Introducing a mini-catamaran to perform reflectance measurements above and below the water surface", Optics Express 13(3), 926-936 (2005).

[2] Froidefond J.M., Castaing P., and R.Prud'homme, "Monitoring suspended particulate matter fluxes and patterns with the AVHRR/NOAA-11 satellite". Application to the Bay of Biscay. Deep-Sea Research II. Special issue Ecofer, 46, 2029-2055 (1999).

[3] Froidefond J.M., Lavender S., Laborde P., Herbland A. and Lafon V., "SeaWiFS data interpretation in a coastal area in the Bay of Biscay". International Journal of Remote Sensing. (23), 5, 881-904 (2002).

[4] Gege, P., "The water color simulator WASI: an integrating software tool for analysis and simulation of optical in situ spectra", Computers \& Geosciences 30, 523-532 (2004).

[5] Lee, Z.P., Carder K.L., Haves S.K., Steward R.G., Peacock T.G., Davis C.O., "Method to derive ocean absorption coefficients from remote sensing reflectance", Applied Optics 20, 177-184 (1996).

[6] Mobley, C.D., [Light and Water], Academic Press, 592 pp. (1994).

[7] Mobley, C.D., and L.K. Sundman., [Hydrolight 4.3 Users Guide]. Sequoia Scientific Inc. 88p. (2007).

[8] Wernand, M.R., Shimwell, S.J., and J.C. De Munck, "A simple method of full spectrum reconstruction from a fiveband approach for ocean colour applications". Int. J. Remote Sensing, 18 (9) 1977-1986 (1997).

[9] Schmeltz, M., Froidefond, J.M., Jourdin, F., Martiny, N., "IOP from reflectance measurements to obtain the Kd coefficient. Application to the Gabon and Congo coastal waters". Ocean Remote Sensing: Methods and Applications, edited by Robert J. Frouin, Proc. SPIE 7459, 74590A1-74590A12 (2009).

[10] Gordon, H.R., Brown O.B. and Jacobs M.M., "Computed relationships between the inherent and apparent optical properties of a flat, homogeneous ocean", Applied Optics 14, 417-427 (1975).

[11] Albert A. and Mobley C.D., "An analytical model for subsurface irradiance and remote sensing reflectance in deep and shallow case-2 waters", Optics Express 11(22), 2873-2890 (2003).

[12] Albert, A., "Inversion technique for optical remote sensing in shallow water", Ph.D. thesis, University of Hamburg. http://www.sub.uni-hamburg.de/opus/volltexte/2005/2325/ (2004).

[13] Albert, A. and Gege, P., "Inversion of irradiance and remote sensing reflectance in shallow water between 400 and $800 \mathrm{~nm}$ for calculations of water and bottom properties", Applied Optics 45(10), 2331-2343 (2006).

[14] Gege, P. and Albert A., "A tool for inverse modelling of spectral measurements in deep and shallow waters", L.L. Richardson and E.F. LeDrew (eds.), Remote Sensing of Aquatic Coastal Ecosystem Processes: Science and Management Applications, 81-109 (2006).

[15] Gordon, H.R. and McCluney W.R., "Estimation of the Depth of Sunlight Penetration in the Sea for Remote Sensing", Applied Optics 14(2), 413-416 (1975).

[16] Jourdin, F., Froidefond, J.M., Loyer, S., Lefèvre, C., Mayoyas, Y.-K., Vrignaud, C. and Kolodziejczyk, N., "Measuring upper ocean turbidity off Congo and Gabon coasts CMM'06", caractérisation du milieu marin. Brest. 16-19 October 2006 (2006).

[17] Petus, C., Chust, G., Gohin, F., Doxaran, D., Froidefond, J.M., Sagarminaga, Y., "Estimating turbidity and total suspended matter in the Adour River plume (South Bay of Biscay) using MODIS 250-m imagery". Continental Shelf Research 30 (5) 379-392 (2010).

[18] Babin, M., Stramski, D., Ferrari, G.M., Claustre, H., Bricaud, A., Obolensky, G. and Hoepffner, N., "Variations in the light absorption coefficients of phytoplankton, nonalgal particles, and dissolved organic matter in coastal waters around Europe", J. Geophys. Res. 108(C7), 3211, (2003). 